We are grateful for help from Dr. J. Laws, Professor A. C. Cunliffe and his staff, Professor J. R. May, of Brompton Hospital, Dr. P. Croydon, of Messrs. Beechams Laboratories, Dr. S. Oram, Dr. P. Kidner, Professor C. H. Gray and his staff, and Professor W. Davidson and his staff. Many others helped us, especially the nursing staff and physiotherapists of King's College Hospital and the technical and secretarial staff of the pulmonary research unit. We wish to thank the Board of Governors and administrative staff for giving permission for this operation in a busy general hospital. Professor Lynne Reid, of the Brompton Hospital, has kindly agreed to do detailed pathological studies of the excised lung. We are especially indebted to Mr. M. Bewick, of Guy's Hospital, not only for the daily rosette test but for continued helpful advice about the immunosuppressive treatment.

\section{References}

Bates, D. V. (1970). New England fournal of Medicine, 282, 277. Bell, P. R. F., et al. (1971). Lancet, 1,876 .
British Medical fournal, 1970, 3, 600.

Derom, F., et al. (1969). Tijdschrift voor Geneeskunde, 25, 109.

Hardy, J. D., Webb, W. R., Dalton, M. L., and Walker, G. R. (1963). Fournal of the American Medical Association, 186, 1065.

Hardy, J. D., et al. (1970). Fournal of Thoracic and Cardiovascular Surgery,

60, 411.
Hugh-Jones, P. (1967). Bulletin de Physio-Pathologie Respiratoire, 3, 419.

Hutchin, P., Freezor, M. D., Walker, E. L., and Peters, R. M. (1971). Journal of Thoracic and Cardiovascular Surgery, 61, 476.

Juvenelle, A. A., Citret, C., Wiles, C. E., and Stewart, J. D. (1951). fournal of Thoracic Surgery, 21,111 .

Munro, A., et al. (1971). British Medical fournal, 3, 271.

Organ Transplant Registry (1971). American College of Surgery/National Institutes of Health, Chicago, Illinois.

Pines, A., Raafat, H., Siddiqui, G. M., and Greenfield, J. S. B. (1970). British Medical fournal, $1,663$.

Sheil, A. G. R., et al. (1971). Lancet, 1, 359.

Stevens, P. M., Johnson, P. C., Bell, R. L., Beall, A. C., and Jenkins, D. E. (1970). New England fournal of Medicine, 282, 245.

Veith, F. J. (1970). Fournal of Thoracic and Cardiovascular Surgery, 60, 423.

Veith, F. J. (1970). Fournal of Thoracic and Cardiovascular
West, J. B. (1960). Fournal of Applied Physiology, 15, 976.

West, J. B. (1960). Fournal of Applied

West, . B. (1963). Lancet, 2, Apps. (1959). Journal of Applicd Physiolog,

West, J. B., and Hugh-Jones, P. (1959). Journal of Applied Physiology, 14,743 .

Wildevuur, C. R. H., and Benfield, J. R. (1970). Annals of Thoracic Surgery, 9, 489 .

\title{
Ophthalmic Manifestations of the Battered-baby Syndrome
}

\author{
BRIAN HARCOURT, DAVID HOPKINS
}

British Medical fournal, 1971, 3, 398-401

\section{Summary}

Eleven battered babies who had ocular manifestations of their abuse are presented. Eight of these suffered a permanent impairment of visual function. Ten had extensive intraocular haemorrhage, and the importance of this physical sign in the diagnosis of the syndrome and in the development of a consequent visual handicap is emphasized.

\section{Introduction}

The battered-baby syndrome occurs in young children who have suffered physical trauma at the hands of their parents or guardians. Affected children often have severe permanent physical, mental, and emotional disabilities, and some die as a result of the abuse. It is clearly of the utmost importance that the diagnosis is never overlooked, and the characteristic association of some or all of the following features has been found most helpful: (1) the child is usually less than 2 years of age; (2) the general condition of the child is often indicative of neglect; (3) there is often a disproportionate amount of soft tissue injury; (4) there may be evidence that the injuries have occurred at different times, and, in particular, radiographic skeletal survey may show that a number of bony fractures are in different stages of resolution; (5) the parents' or guardians' history is inadequate and incompatible with the demonstrable injuries; and (6) there is often a history of multiple admissions to hospital, and characteristically no new lesions appear during the child's stay in hospital (modified from Birrell and Birrell, 1968).

Leeds General Infirmary, Leeds LS1 3EX

BRIAN HARCOURT, F.R.C.S., D.o., Consultant Ophthalmic Surgeon DAVID HOPKINS, F.R.C.S., D.o., Senior Registrar in Ophthalmology
Despite detailed descriptions of external, visceral, skeletal, craniocerebral, and psychiatric findings in affected children (Caffey, 1946; Silverman, 1953; Kempe et al., 1962; Griffiths and Moynihan, 1963; McCort and Vaudagna, 1964; Cameron et al., 1966; Isaacs, 1968; Sussman, 1968) little attention has hitherto been directed to the ophthalmic manifestations. It is therefore our purpose to present the ocular findings in 11 young children who fulfil the diagnostic criteria of the syndrome so as to draw further attention to this important aspect of the disorder, demonstrating that in some cases severely defective vision may be a principal feature of a surviving child's permanent disability.

\section{Case Reports}

Tables have been used in order to present a summary of the principal general manifestations (Table I) and of the ophthalmic manifestations (Table II) in all the patients examined in this study. The ophthalmic examinations were carried out at intervals ranging from a few days to three years after the major episode of trauma, and the progress of most of the patients has

TABLE I-Case Histories: General Manifestations

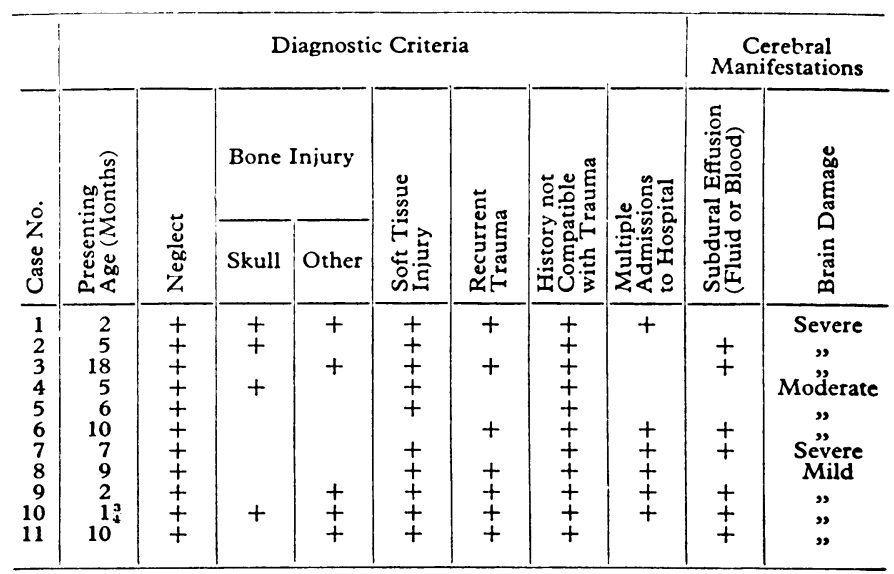


TABLE II-Case Histories: Ophthalmic Manifestations

\begin{tabular}{|c|c|c|c|c|c|c|c|c|c|c|c|c|c|c|c|c|c|c|c|}
\hline \multirow{4}{*}{ Case No. } & \multicolumn{7}{|c|}{ Acute Ocular Signs } & \multicolumn{6}{|c|}{ Ocular Sequelae } & \multirow{3}{*}{\multicolumn{2}{|c|}{$\begin{array}{l}\text { Visual } \\
\text { Responses* }\end{array}$}} & \multicolumn{4}{|c|}{$\begin{array}{l}\text { Localization of Principal } \\
\text { Cause of Visual Defect }\end{array}$} \\
\hline & \multirow{3}{*}{$\begin{array}{l}\text { Periorbital } \\
\text { Haematoma }\end{array}$} & \multicolumn{6}{|c|}{ Intraocular Haemorrhage } & \multirow{2}{*}{\multicolumn{2}{|c|}{$\begin{array}{l}\text { Organized } \\
\text { Vitreous }\end{array}$}} & \multirow{2}{*}{\multicolumn{2}{|c|}{$\begin{array}{c}\text { Macular } \\
\text { Disturbance }\end{array}$}} & \multirow{2}{*}{\multicolumn{2}{|c|}{$\begin{array}{l}\text { Optic } \\
\text { Atrophy }\end{array}$}} & & & \multirow{2}{*}{\multicolumn{2}{|c|}{$\begin{array}{l}\text { Intra- } \\
\text { ocular }\end{array}$}} & \multirow{3}{*}{$\begin{array}{l}\text { Visual } \\
\text { Pathways }\end{array}$} & \multirow{3}{*}{$\begin{array}{l}\text { Visual } \\
\text { Cortex }\end{array}$} \\
\hline & & \multicolumn{2}{|c|}{ Vitreous } & \multicolumn{2}{|c|}{ Preretinal } & \multicolumn{2}{|c|}{ Retinal } & & & & & & & & & & & & \\
\hline & & $\mathbf{R}$ & L & $\mathbf{R}$ & $\mathrm{L}$ & $\mathbf{R}$ & L & $\mathbf{R}$ & $\mathbf{L}$ & $\mathbf{R}$ & $\mathbf{L}$ & $\mathbf{R}$ & L & $\mathbf{R}$ & $\mathbf{L}$ & $\mathbf{R}$ & $\mathbf{L}$ & & \\
\hline $\begin{array}{r}1 \\
2 \\
3 \\
4 \\
5 \\
6 \\
7 \\
8 \\
9 \\
10 \\
11\end{array}$ & $\begin{array}{l}+ \\
+\end{array}$ & $\begin{array}{l}+ \\
+\end{array}$ & $\begin{array}{l}+ \\
+\end{array}$ & $\begin{array}{l}+ \\
+ \\
+ \\
+ \\
+ \\
+ \\
+ \\
+\end{array}$ & $\begin{array}{l}+ \\
+ \\
+ \\
+ \\
+ \\
+ \\
+ \\
+\end{array}$ & $\begin{array}{l}+ \\
+ \\
+ \\
+ \\
+ \\
+ \\
+ \\
+\end{array}$ & $\begin{array}{l}+ \\
+ \\
+ \\
+ \\
+ \\
+ \\
+ \\
+\end{array}$ & + & + & + & $\begin{array}{l}+ \\
+ \\
+ \\
+\end{array}$ & $\begin{array}{l}+ \\
+\end{array}$ & $\begin{array}{l}+ \\
+ \\
+ \\
+ \\
+\end{array}$ & $\begin{array}{l}\mathbf{A} \\
\mathbf{A} \\
\mathbf{N} \\
\mathbf{N} \\
\mathbf{S} \\
\mathbf{N} \\
\mathbf{A} \\
\mathbf{S} \\
\mathbf{N} \\
\mathbf{N} \\
\mathbf{N}\end{array}$ & $\begin{array}{l}\mathbf{A} \\
\mathbf{S} \\
\mathbf{A} \\
\mathbf{A} \\
\mathbf{S} \\
\mathbf{A} \\
\mathbf{A} \\
\mathbf{S} \\
\mathbf{N} \\
\mathbf{N} \\
\mathbf{N}\end{array}$ & $\begin{array}{l}+ \\
+\end{array}$ & $\begin{array}{l}+ \\
+ \\
+ \\
+\end{array}$ & $\begin{array}{l}+ \\
+ \\
+ \\
+ \\
+\end{array}$ & $\begin{array}{l}+ \\
+\end{array}$ \\
\hline
\end{tabular}

- $\mathrm{A}=$ Absent. $\mathrm{N}=$ Normal. $\mathrm{S}=$ Subnormal.

been followed during a period of more than 12 months. The ocular manifestations listed in Table II therefore represent an evolution of the results of ocular trauma over a considerable period of time, rather than a summary of simultaneous observations. Evidence of the cerebral manifestations is based on clinical assessment, on findings at operation, on electroencephalography (E.E.G.), and in two cases on postmortem appearances.

\section{CASE 1}

This male child was the result of an unwanted pregnancy; the parents were very recently married and both came from problem families. The father was aggressive and had a prison record; the home conditions were poor, and the parents had considerable financial worries. Pregnancy and delivery were uneventful and the child was believed to be in good health until he was admitted to hospital at the age of 2 months with a fracture of the right femur. The parents said that he had fallen from a sofa. He was readmitted at the age of 4 months with a refracture at the same site and a diagnosis of "battered baby" was suspected at that time, but it could not be substantiated and the child was discharged again to the parents' care.

He was lost to follow-up until the age of 9 months, when he was readmitted in a comatose state with no satisfactory history. He was then found to have a fracture of the left parietal bone and signs of severe diffuse cerebral damage; bilateral extensive peretinal and retinal haemorrhages were present, but no subdural effusion was discovered. Though the child survived these injuries he was at the time of writing severely mentally and physically retarded and was subject to major convulsions. Clinically there had been no evidence of any response to visual stimuli since his cerebral injuries occurred. $\mathrm{He}$ has been followed up in the paediatric ophthalmic clinic until the time of writing, and was then aged 30 months. Eye movements appeared full and there was no squint or nystagmus. The intraocular haemorrhages had cleared without trace of residual retinal scarring, but there was pronounced bilateral optic atrophy. An assessment of visually evoked cortical responses had been made on two occasions during the past year, and no primary or secondary responses had been discerned. As the pupils reacted quite briskly to light, this inferred that there was an element of cortical blindness in addition to the optic atrophy.

Diagnosis.-General: Severe diffuse brain damage following skull fracture. Ocular: Bilateral optic atrophy and cortical blindness.

\section{CASE 2}

This male child's history was unremarkable until the age of 5 months, when he was brought by a foster parent to hospital with a history of drowsiness and convulsions over the previous two days. He appeared to be underweight and neglected, and there was never any convincing explanation given of the injuries which were subsequently discovered. On admission extensive bruising of the forehead was noted, and radiological examination showed a fracture of the left frontal bone. Bilateral subdural effusions were tapped on a number of occasions and a cavernous sinus thrombosis was suspected on clinical grounds. Extensive vitreous haemorrhages were noted in the right eye and preretinal and retinal haemorrhages in the left eye at the time of this original admission.

Despite energetic treatment the child was left with a severe degree of mental and physical retardation, and an E.E.G. at the age of 4 years showed a very severe diffuse abnormality affecting both cerebral hemispheres with no paroxysmal features. At that time a further thorough ophthalmic examination was carried out. The right eye was found to be blind with a pronounced divergent squint and no direct pupillary light reflex; the anterior segment was healthy, but there was an extensive organized vitreous haemorrhage. No clear view of the undelying retina could therefore be obtained, but it was thought that a traction retinal detachment was present. Fixation of the left eye was very unsteady with irregular wandering movements, and visual responses were evoked only with large moving targets or wide stripes; the left pupil reacted sluggishly to direct light. There was extensive scarring and puckering of the macula and the optic disc was very pale (Fig. 1). On account of the child's age and mental retardation no accurate subjective assessment of visual acuity was possible, but from clinical observation it was thought that the acuity of the left and only seeing eye was certainly no more than $6 / 60$.

Diagnosis.-General: Severe diffuse brain damage following skull fracture, subdural haematomata, and suspected cavernous sinus thrombosis. Ocular: Right eye, blind and divergent with an organized vitreous haemorrhage and probably traction detachment of the retina. Left eye, permanent defect of central vision with macular scarring and optic atrophy.

\section{CASE 3}

This child was believed to be in good health until the age of 18 months, when, under the temporary care of a child minder, he was found unconscious and was brought to hospital in a state of respiratory collapse. The child appeared ill-nourished and there were multiple bruises on the forehead, chin, trunk, and limbs, and burns were present on both buttocks. A radiological skeletal survey showed the presence of an old poorly united fracture of the left ulna. The cerebrospinal fluid was blood-stained, and bilateral subdural hygromata were discovered. Extensive bilateral preretinal and retinal haemorrhages were present, and at that early stage of the child's illness there were no responses to visual stimuli except for a blink reflex to threat. The intraocular haemorrhage cleared within six weeks with no observable residual retinal scarring, but the child developed a pronounced pallor of the left optic disc and a left divergent squint. There was no nystagmus. The child had remained mentally and physically retarded, and subsequent air studies have shown a widespread cortical atrophy, and there was also E.E.G. evidence of diffuse cerebral damage. Visual responses with the right eye were quite good, but clinical observation strongly suggested that the left eye was blind.

Diagnosis.-General: Extensive cerebral damage following bilateral subdural hygromata. Ocular: Right eye, normal. Left eye, divergent with optic atrophy. 


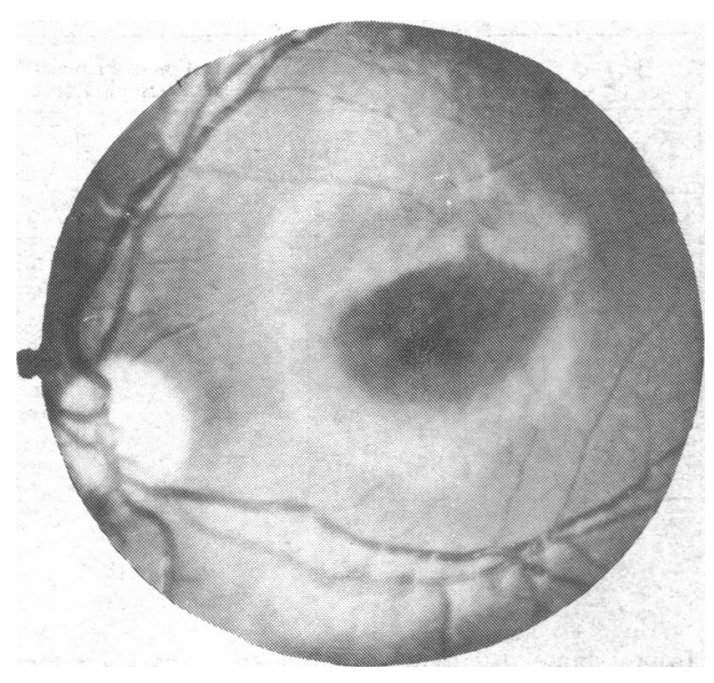

FIG. 1-Case 2. Left eye showing macular scarring and pale optic disc.

\section{CASE 4}

This child was brought to hospital at the age of 5 months because of an enlarging swelling on the left side of the head. A traumatic meningocele was found associated with a fracture of the left parietal bone. There was bruising on the face and limbs, and superficial scars were noted on the left arm and hand. No adequate explanation of these injuries was ever given, and there was strong circumstantial evidence that they were not accidental. At the time of admission to hospital bilateral preretinal and retinal haemorrhages were noted, and these extended into the vitreous, especially in the right eye, obscuring any clear view of the optic discs. Ocular examination was otherwise unremarkable. The haemorrhages subsequently cleared and at the age of 17 months the right eye was normal, but there was macular scarring and optic atrophy in the divergent left eye, the vision of which was markedly defective. The child had had major convulsions, and was mentally and physically retarded with a right hemiparesis.

Diagnosis.-General: Traumatic parietal meningocele with severe permanent cerebral damage. Ocular: Right eye, normal. Left eye, divergent squint with macular scarring and optic atrophy.

\section{CASES 5-8}

These four additional tabulated cases had many important features

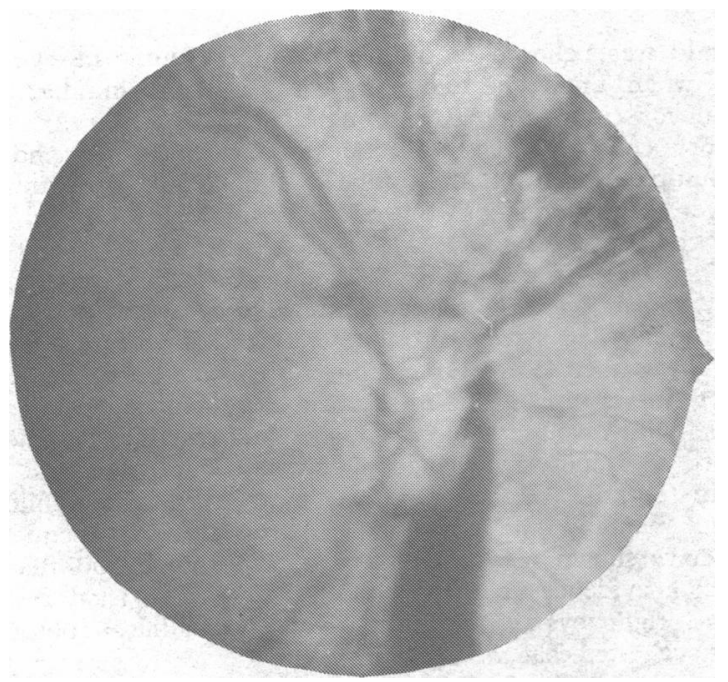

FIG. 2-Case 9. Right eye showing preretinal and retinal haemorrhages with venous distension. exemplifying the ophthalmic sequelae of the battered-baby syndrome, resulting in permanent visual handicap.

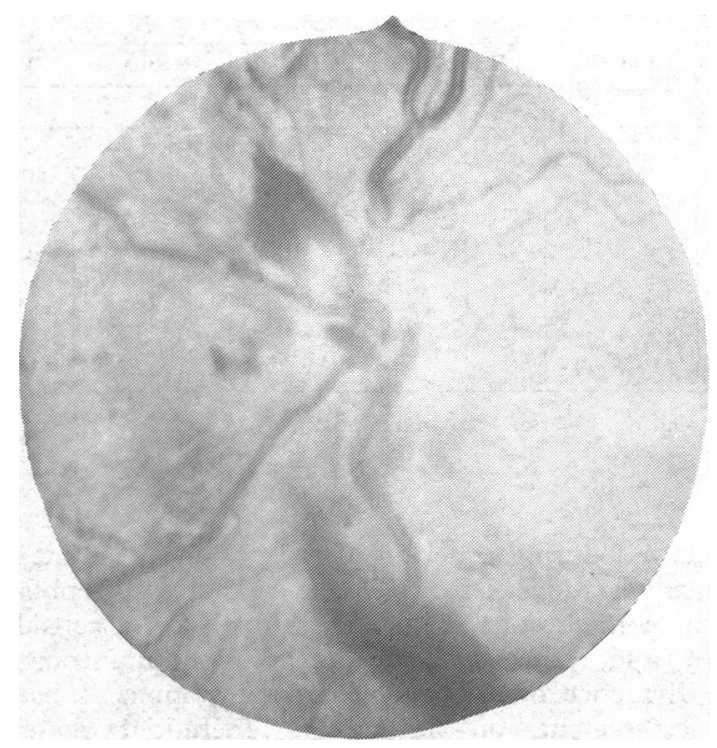

FIG. 3-Case 9. Left eye showing preretinal and retinal haemorrhages with venous distension.

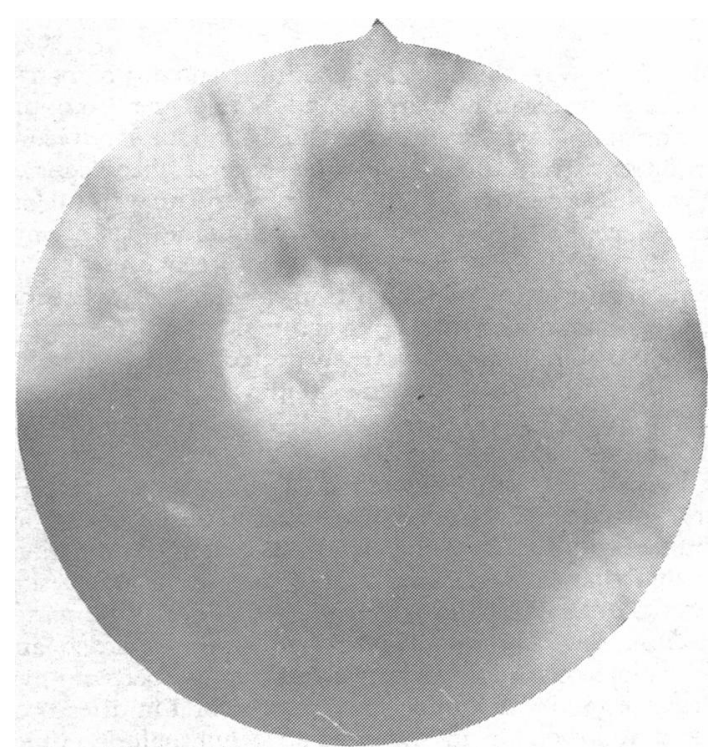

FIG. 4-Case 11. Right eye showing extensive preretinal haemorrhages around the optic disc.

\section{CASES 9-11}

We have also examined and observed over a considerable period three other battered babies who suffered subdural effusions and who were noted to have very extensive bilateral preretinal and retinal haemorrhages in the early period of their convalescence (Figs. 3-5). In these three cases the intraocular bleeding fortunately cleared without any evidence of consequent macular scarring or visual defect.

\section{Discussion}

All the cases described were either referred direct to the paediatric ophthalmic clinic at the Leeds General Infirmary for ophthalmic opinion or were referred in response to a request. 


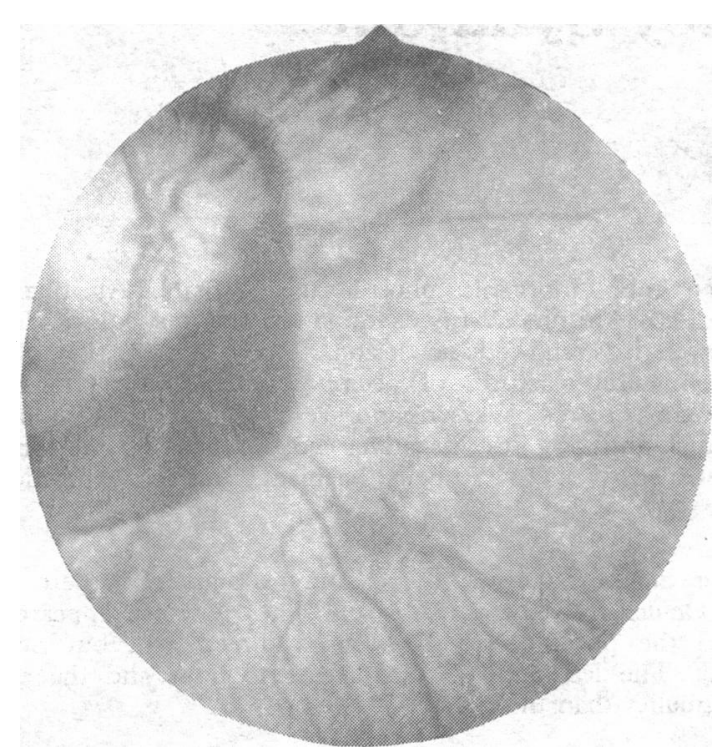

FIG. 5-Case 11. Left eye showing extensive preretinal haemorrhages around the optic disc

circulated to consultant paediatric physicians in the Leeds Region for permission to examine battered children in their care. The cases must, therefore, be regarded as a selected series and they do not give an accurate reflection of the incidence of ophthalmic manifestations in the syndrome overall. The results of the present investigation do, however, emphasize that severe permanent visual handicap, amounting in some cases to blindness, does affect a significant number of battered children.

A review of the rather sparse literature of the subject shows that the principal ophthalmic manifestations of the batteredbaby syndrome which have been described previously are injuries to the eyelids (Woolley and Evans, 1955; Cameron et al., 1966), posterior subcapsular cataracts (Kiffney, 1964; Fessard et al., 1967), peripheral choroidoretinal atrophy (Maroteaux et al., 1967; Maroteaux and Lamy, 1967), and preretinal and retinal haemorrhages (Gilkes and Mann, 1967). The significant features in the present series of patients are the paucity of external ocular trauma and the absence of anterior segment damage, the development of optic atrophy and cortical blindness in a significant number of cases, and, most strikingly, the extreme frequency of extensive intraocular haemorrhages at the time of the major incident of trauma, with subsequent macular scarring in four cases of vitreous organization in two cases. In 9 of the 10 cases with intraocular bleeding there was either a skull fracture or evidence of major soft-tissue injury to the head, and in six of these children a subdural effusion was discovered. In Cases 1, 4, 5, and 8, however, despite pronounced bilateral fundus haemorrhages, there was no evidence of a subdural haematoma or hygroma.
Many authors have reported the association of intraocular haemorrhage with subdural haematoma in infants (Hollenhorst and Stein, 1958; Russell, 1965; Till, 1968), but Gilkes and Mann (1967) were the first to suggest that very severe intraocular haemorrhage might indicate that physical abuse had occurred. They felt that such bleeding might be the result not only of cranial trauma and the subsequent development of subdural effusions, but also of constrictive chest injury and of the gravitational effects which would result if a child were swung round by the feet. These suggestions were based on the clinical observation of several relevant and well-documented cases, and the authors concluded that though the possibility of physical maltreatment had to be considered in all young children with subdural effusions the presence of gross intraocular haemorrhage and distended retinal veins, sometimes associated with papilloedema and exudates, should considerably increase the clinician's suspicions.

The very common occurrence of intraocular haemorrhages both in the presence and in the absence of subdural effusions (though with the probability of other intracranial haemorrhage) in the known battered babies that we have examined would seem to substantiate this previous clinical observation. The finding of consequent macular scarring of a sufficient degree to cause a pronounced permanent defect in central visual acuity in several cases suggests that the presence of severe intraocular haemorrhages should not only raise the suspicion of battering but should also lead to a very cautious initial assessment of the chances for an eventual recovery of full visual function.

We are indebted to Professor F. W. Smithells, Dr. M. F. G. Buchanan, Dr. M. W. Arthurton, Mr. R. Myles Gibson, and Mr. W. C. Thornhill for allowing us to study patients under their care.

\section{References}

Birrell, R. G., and Birrell, J. H. W. (1968). Medical fournal of Australia, 2,1023

Caffey, J. (1946). American fournal of Roentgenology, Radium Therapy, and Nuclear Medicine, 56, 163.

Cameron, J. M., Johnson, H. R. M., and Camps, F. E. (1966). Medicine,

Science and Law, 6, 2.
Fessard, C., Maroteaux, P., and Lamy, M. (1967). Archives Frangaises de Pédiatrie, 24, 651 .

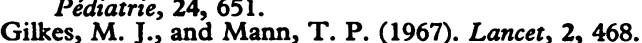

Gilkes, M. J.) and Mann, T. P. (1967). Lancet, 2, 468.

Hollenhorst, R. W., and Stein, H. A. (1958). Archives of Ophthalmology, 60,187

Isaacs, S. (1968). Lancet, 1, 37.

Kempe, C. H., Silverman, F. N., Steele, B. F., Droegemueller, W., and Silver, H. K. (1962). Fournal of the American Medical Association, 181,17 .

Kiffney, G. T., jun. (1964). Archives of Ophthalmology, 72, 231

McCort, J. J., and Vaudagna, J. (1964). Radiology, 82, 424.

Maroteaux, P., Fessard, C., and Aron, J. J. (1967). Presse Médicale, 75, 711.

Maroteaux, P., and Lamy, M. (1967). Lancet, 2, 829.

Silverman, F. N. (1953). American fournal of Roentgenology, 69, 413.

Sussman, S. J. (1968). Fournal of Pediatrics, 72, 99 .

Sussman, S. J. (1968), fournal of Pediatrics, 72,

Woolley, P. V., jun., and Evans, W. A. (1955). fournal of the American Medical Association, 158, 539. 